\title{
Environmental Sampling for Legionella Proliferation Risk in Three Long-Term Care Facilities in Vancouver, British Columbia
}

\author{
Kelsey A. Stele ${ }^{1}$, Helen Heacock ${ }^{2}$ \\ ${ }^{1}$ Lead author, B. Tech Student, School of Health Sciences, British Columbia Institute of Technology, 3700 Willington Ave, Burnaby \\ ${ }^{2}$ Supervisor, School of Health Sciences, British Columbia Institute of Technology, 3700 Willington Ave, Burnaby
}

\section{ABSTRACT:}

Background: Legionella is a pathogen that causes Legionnaires' disease in high risk populations. The pathogen is known to exist in plumbing systems that do not have preventative factors in place to prevent its growth and proliferation. Legionella grows between $25^{\circ} \mathrm{C}$ and $42^{\circ} \mathrm{C}$ and is killed at $60^{\circ} \mathrm{C}$, yet longterm care facilities (LTCFs) reduce accessible hot water temperatures from $60^{\circ} \mathrm{C}$ at the hot water tank to less than $49^{\circ} \mathrm{C}$ at the taps in order to prevent scalding of their residents. Currently, prevention against scalding takes precedence as temperature at accessible taps is regulated within the Residential Care Regulation (RCR) of the Community Care and Assisted Living Act. It is thought that Legionella proliferation risk can be balanced with scalding in-part through the appropriate installation location of thermostatic mixing valves (TMVs).

Methods: Three LTCFs in Vancouver, British Columbia were selected for environmental sampling for Legionella proliferation risk. At each LTCF the author recorded the type of hot water tank, temperature of water within the hot water tank, the presence of a TMV and temperature of pipes before and after the TMV. As well, the author recorded hot water temperatures after one minute and free available chlorine concentration ([FAC]) at numerous resident-accessible taps throughout each LTCF.

Results: The hot water tank temperatures were set at $60.6^{\circ} \mathrm{C}, 73.0^{\circ} \mathrm{C}$ and $62.0^{\circ} \mathrm{C}$ for LTCF \#1, LTCF \#2 and LTCF \#3, respectively. All three LTCFs had installed a TMV within the boiler room immediately after the hot water tank. It was found that LTCF \#1's plumbing system water temperature was reduced from $60.6^{\circ} \mathrm{C}$ (at the tank) to $48.9^{\circ} \mathrm{C}$ after the TMV. LTCF \#2's plumbing system water temperature was reduced from $73.0^{\circ} \mathrm{C}$ (at the tank) to $43.3^{\circ} \mathrm{C}$ after the TMV. LTCF \#3 was an older plumbing system that did not have thermometers within the boiler room to check the drop in temperature after the TMV. Water temperatures at taps were compared to a standard of $49^{\circ} \mathrm{C}$ and [FAC] levels at taps to a standard of 0.2 $\mathrm{mg} / \mathrm{L}$. The mean hot water temperature and mean [FAC] residual for all three LTCFs were $40.2^{\circ} \mathrm{C}$ and $0.27 \mathrm{mg} / \mathrm{L}$, respectively. For all three LTCFs, it was statistically significant that mean water temperatures were less than the comparison value of $49^{\circ} \mathrm{C}$ (LTCF \#1 $p=0.00000$, LTCF \#2 $p=0.00022$, LTCF \#3 $p$ $=0.00110$ ). It was also statistically significant that the mean [FAC] of all three LTCFs were greater than the comparison vale of $0.20 \mathrm{mg} / \mathrm{L}$ (LTCF \#1 $\mathrm{p}=0.00042$, LTCF \#2 p =0.00000, LTCF \#3 p=0.00107). Conclusion: It was found that all three LTCFs had set preventive measures in place to protect their residents. Water was heated to at least $60^{\circ} \mathrm{C}$ to prevent Legionella and lowered to less than $49^{\circ} \mathrm{C}$ to prevent scalding. [FAC] residual was also adequate to prevent growth of Legionella. However, the location of the TMV in the boiler room was suspected to be a possible contributing factor to Legionella growth, especially if cold water temperatures were to reach $20^{\circ} \mathrm{C}$ or above, as they could in warm summer months. Further research is needed to determine the significance of the TMV location and the presence of Legionella.

Keywords: Legionella pneumophila, Legionnaires' disease, Pontiac fever, community care facility, long-term care facility, high risk population, free available chlorine concentration, hot water temperature, hot water tank, thermostatic mixing valve 


\section{INTRODUCTION:}

The author of this report was interested in environmental conditions that may encourage the risk of Legionella proliferation and therefore potential for Legionnaires' disease infection in a vulnerable population. As such, the author collected environmental samples for Legionella proliferation risk at three long-term care facilities (LTCFs) within Vancouver, British Columbia. These samples included recording hot water tank temperatures, the location of thermostatic mixing valves (TMVs), plumbing piping temperatures where available, as well as hot water temperatures and free available chlorine concentrations ([FAC]) at accessible taps.

\section{BRIEF EVIDENCE REVIEW:}

Legionella is a human pathogen that can cause two different types of illnesses: Legionnaires' disease and Pontiac fever. Collectively, these illnesses are referred to as legionellosis. Legionnaires' disease presents itself as pneumonia characterized by fever, dry cough, dyspnea, chest pain, headache, malaise and myalgia $(1,2)$. The respiratory infection is often severe and can progress to respiratory and multiorgan failure, with death rates of up to $10 \%$ or as high as $40-80 \%$ in untreated immune-suppressed patients $(3,4)$. Of the 50 species and 70 serotypes of Legionella, Legionella pneumophili serotype 1 causes approximately $70 \%$ of Legionnaires' disease cases (2). Those with lung conditions or compromised immune systems (e.g. transplant and chemotherapy recipients, persons with diabetes or kidney disease) are thought to be at highest risk of contracting Legionnaires' disease (5). The risk is made higher among persons aged 40 to 70 (5). Additional risk factors for Legionnaire's disease include smoking and excessive use of alcohol (5). The infectious dose (i.e. the number of Legionellae cells inhaled) to cause disease is not well understood (6). Pontiac fever, the second illness that Legionellae can cause, is a less serious respiratory illness than Legionnaires' disease. It does not involve pneumonia, but is more flu-like instead (fever, headache, chills) (7). The body is typically capable of resolving Pontiac fever without treatment within 2-5 days of symptom onset $(1,8)$. According to Health Canada, no known fatalities have been reported with Pontiac fever (8).

Currently, legionellosis is listed by the British Columbia Centre for Disease Control (BCCDC) as a reportable disease under Schedule B: Reportable by Laboratories only (9). This means that regular reporting of disease data occurs by passive surveillance. In other words, local laboratories report confirmed cases of legionellosis to a higher administrative level, but there is no active search for cases in the community (10). Passive surveillance contributes to the underestimation of Legionnaire's disease, along with its difficulty to diagnose (4). The most recent British Columbia Annual Summary of Reportable Disease (2016) by BCCDC indicated that legionellosis had dropped slightly from 0.5 cases per 100,000 in 2015 to 0.29 cases per 100,000 in 2016 (11). However, legionellosis continues to show an increasing trend over the last decade (11). The reasons for increased cases are unclear but could be related to increasing use of urine antigen testing in the previous few years $(11,12)$. The majority of cases in British Columbia were reported from Fraser Health Authority $(n=8)$ in 2016 and were likely a result of the region's higher usage of urine antigen testing (11).

Legionella is a gram-negative bacteria that is widespread within the natural water environment and in most soils and mud (13). It has been associated most frequently with plumbing systems, especially in larger buildings, which often have more complex water systems (14). Examples of plumbing systems include: cooling towers, hot water tanks, showers and aerators (6). When a tap from an infected source (e.g. water outlet) is used, sprays or droplets of water containing legionellae can become aerosolized (15). When this occurs, most or all of the water in the droplet evaporates quickly, leaving airborne particulate matter that is small enough to be inhaled (15). Particles of less than $5 \mu \mathrm{m}$ in diameter can be deeply inhaled, and enter the respiratory airways to cause legionellosis (15). 
Direct person-to-person transmission is not considered a risk (8). There has, however, been one case of probable person-to-person transmission reported in Portugal in 2014 (16).

In British Columbia, L. pneumophila caused two outbreaks between 2005 and 2016 (1). The first outbreak ( 5 cases) was associated with a cooling tower and the source of the 2014 outbreak (3 cases) was not confirmed, but thought to be associated with a dishwasher in a food service establishment (1). While British Columbia has not had an outbreak associated with a LTCF, the severity and consequences could prove to be quite devastating. At a Quincy, Illinois veterans' home in 2015, an outbreak of Legionnaires' disease resulted in 12 deaths and at least 54 people sickened (17). The impact of such Legionella outbreaks affect not only the health and wellbeing of the population, but also strains the economy as well, with an estimated cost of \$433 million a year attributed to impatient costs in the U.S. (18)

Many factors may contribute to Legionella growth within a plumbing system. These factors include biofilm formation, the type of disinfection system, a lack or absence of disinfection residual, a lack of thermal control, the type of hot water heater, the amount of scale/corrosion within the pipes and areas in the system with low flow (e.g. dead-ends, absence of mixing valves and point-of-use, incorrect piping diameter) (1).

Since freshwater and man-made water systems are variable, generally low-nutrient environments, Legionella spp. developed mechanisms to acquire nutrients by residing in biofilms (6). Biofilms are capable of covering the interior of pipe walls, in-premise plumbing fixtures and heating, ventilation and airconditioning systems (6). Biofilms not only allow Legionella spp. access to nutrients, but provide a niche and protection against adverse conditions like chlorine and elevated water temperatures (8).

Thriving growth temperature for Legionella lies between $25^{\circ} \mathrm{C}$ and $42^{\circ} \mathrm{C}$, with an optimal growth temperature of $35^{\circ} \mathrm{C}(19)$. The bacteria, however, have also been isolated in water systems at temperatures up to $60^{\circ} \mathrm{C}$ and below $20^{\circ} \mathrm{C}(20,21)$. The National Plumbing Code of Canada (NRCC) includes requirements for maintaining domestic hot water tank temperature at a minimum of $60^{\circ} \mathrm{C}$ to address the growth of Legionella $(8,22)$. One study found that if the water heater temperature was $60^{\circ} \mathrm{C}$ and maintained at least at $55^{\circ} \mathrm{C}$ across the network, there was no risk for Legionella based on negative culture or qPCR results (23). Taking these temperatures into consideration, it is reasonable to require that $\mathrm{LTCF}$ licensees maintain their heater temperature at $60^{\circ} \mathrm{C}$ and the network at $55^{\circ} \mathrm{C}$ across. According to the World Health Organization (WHO), maintaining circulating hot water at $>50^{\circ} \mathrm{C}$ and cold water $<25^{\circ} \mathrm{C}$ is sufficient (24). There is, however, a balancing act between risk of Legionella proliferation and risk of scalding (25). Water at $60^{\circ} \mathrm{C}$ can result in a second-degree burn after three seconds, and a third-degree burn after five seconds in adults (26). As such, the water accessible to a person in care should be lowered to $49^{\circ} \mathrm{C}$ according to the Residential Care Regulation (RCR) Section 17 under the Community Care and Assisted Living Act (27). To reduce the risk of scalding, thermostatic or pressure-balanced mixing valves should be installed to control the water temperature at the tap (28). Instead of inserting thermostatic or pressure-balanced mixing valves directly at taps, buildings may lower the water temperature coming directly out of the hot water tank. This may lead to conditions that facilitate the growth for Legionella if the water in the pipes is circulating at less than $50^{\circ} \mathrm{C}$, and especially if near $35^{\circ} \mathrm{C}$.

The type of water heater system a building uses can make a difference for Legionella growth. After studying hot water plumbing systems in Quebec homes in 1991, researchers Alary and Joly found Legionella in 39\% (69/178) of hot water tanks with electric heaters and $0 \%(0 / 33)$ of tanks with oil-fired or gas-fired heaters. The reason for Legionella detection in electric tanks was determined to be due to the location of the heating elements, which were above the bottom 
of the heaters. This could allow for bottom sediments and a stratification in temperatures, such that water below the heating element remain at lower temperatures capable of Legionella growth (29).

In addition to temperature control, a number of disinfection strategies have been shown to be effective in reducing Legionella, including chlorine, monochloramine, chlorine dioxide, ozone and ultraviolet (UV) radiation (30). A disinfectant residual is important however, and UV does not provide one and chlorine dioxide and ozone are not effective at maintaining a residual (30). A free chlorine concentration of $0.25 \mathrm{mg} / \mathrm{l}$ is capable of maintaining non-biofilm associated Legionella under levels capable of causing disease (31). This is close to the typical free chlorine concentration required in distribution systems $(0.2 \mathrm{mg} / \mathrm{L})$ (32). However, Cervero-Aragó et al. (2015) found that when comparing five different Legionella strains, $L$. pneumophila serotype 1 was the most resistant to the free available chlorine concentrations typical of drinking water systems $(0.2 \mathrm{mg} / \mathrm{L}$ and 0.5 $\mathrm{mg} / \mathrm{L}$ ). Additionally, when Legionella was cocultured with an amoeba (protozoan host), the effectiveness of chlorine treatments on the associated bacteria was reduced between 2.5 and 4 times at $0.5 \mathrm{mg} / \mathrm{L}$ (33). Some plumbing systems of hospitals and large buildings employ routine thermal disinfection either on its own or in conjunction with chemical disinfection as a means of a temporary control strategy (34).

Since there is uncertainty about what concentration of Legionellae cells is required to cause infection (35) and no private labs in western Canada are currently engaged in environmental sample analysis [note: BCCDC Public Health Laboratory is working towards a quicker and improved method of Legionella detection in water and on swabs (36)], it does not make sense to gather water samples to test for Legionella. In the end, it is the factors for growth discussed above that will contribute to Legionella growth in a water system and testing for its presence only confirms that.
Plumbing systems are frequently old and complex, favoring amplification of Legionella bacteria; and water temperatures are often reduced to prevent scalding of patients (37). While the VCH's Residential Facility Inspection Checklist requires the Licensing Officer to check water temperatures that are accessible to people in care (38), the responsibility to maintain water temperatures actually falls under the care facility licensee according to the Residential Care Regulation under the Community Care and Assisted Living Act (27). Since maintaining water system temperatures and chlorine residual minimizes the likelihood of Legionnaires' disease transmission, the purpose of the author's research study is to determine whether LTCFs are abiding by temperatures and disinfection conditions nonconductive to the growth of Legionella. While temperature and chlorine residual are not the final indicators of Legionella presence, they offer insight into the current maintenance of the water network. It is thought that prevention efforts may be inadequately implemented in the majority of health care facilities, especially if the facility is old and/or not measuring risk of scalding against risk of Legionella.

\section{METHODOLOGY}

Three LTCFs housing senior residents within the city of Vancouver were selected for testing based on accessibility. At each LTCF, the following methods were conducted, which were split into two stages: Hot water tank and piping temperatures within the boiler room, and temperature and chlorine measurements at faucets.

\section{A. Hot Water Tank and Piping Temperatures within Boiler Room}

With maintenance personnel for access and reference, the LTCF's boiler room was visited. The following information was recorded: the type of hot water heater the facility used (gas or electric), the temperature output at the hot water tank, the water holding tank temperature (if available) and the temperature of any plumbing 
lines by reading plumbing line thermometers (if available). It was also determined whether there was a TMV located within the boiler room or elsewhere. If there was a TMV in the boiler room, the temperature of the water entering and existing the TMV were both recorded by reading plumbing line thermometers (if possible).

\section{B. Temperature and Chlorine Measurements at Faucets}

30 resident-accessible taps were chosen to give a good representation of the entire LTCF building (e.g. taps on every floor or every other floor, either end of the floor and the middle of the floor) for temperature and chlorine measurements. For statistical validity, measurement at 30 taps was sought after.

At each tap, it was recorded whether the tap had a TMV. The TMV could be discovered by looking under the sink. A clean (rinsed with distilled water), double-cupped $16 \mathrm{oz}$ Solo cup was placed under the faucet and the hot water was turned on for one minute. The water overfilled the cup. Time was recorded with a stop watch. After one minute, the hot water was turned off and the temperature of the water within the Solo cup was immediately recorded using a calibrated, clean BIOS DT130 pocket digital thermometer. Following temperature measurement, the [FAC] of the hot water in the Solo cup was recorded using a LaMotte ColorQ PRO 7 kit by following the kit's instruction manual for [FAC]. After temperature and chlorine measurements at each tap, the thermometer, Solo cup, and LaMotte ColorQ PRO 7 equipment were rinsed with distilled water to remove any chlorine residue.

\section{RESULTS:}

The LTCFs varied in size from two floors (LTCF \#3) to four floors (LTCF \#2) to 15 floors (LTCF \#1).

The author found that all three LTCFs had domestic gas-fired hot water tanks installed to supply hot water to residents. The hot water tank temperatures were set at $60.6^{\circ} \mathrm{C}, 73.0^{\circ} \mathrm{C}$ and $62.0^{\circ} \mathrm{C}$ for $\mathrm{LTCF} \# 1, \mathrm{LTCF} \# 2$ and LTCF \#3, respectively.

The author found that all three LTCFs had installed a TMV within the boiler room immediately after the hot water tank. There were no TMVs directly at accessible taps within the facility, except where a resident-accessible tap may be connected to a kitchen plumbing line where hot water was needed for regular kitchen duties. The hot water tank heated incoming municipality-treated water to $60^{\circ} \mathrm{C}$ and sent it through the TMV, where the water temperature was cooled to less than $49^{\circ} \mathrm{C}$ by mixing in cold water. Where there was a thermometer to read the temperature of the water in the pipes coming out of the TMV, it was recorded by the researcher. It was found that LTCF \#1's plumbing system water temperature was reduced from $60.6^{\circ} \mathrm{C}$ (at the tank) to $48.9^{\circ} \mathrm{C}$ after the TMV. LTCF $\# 2$ 's plumbing system water temperature was reduced from $73.0^{\circ} \mathrm{C}$ (at the tank) to $43.3^{\circ} \mathrm{C}$ after the TMV. LTCF \#3 was an older plumbing system that did not have thermometers within the boiler room to check the drop in temperature after the TMV. Instead, the maintenance staff routinely checked hot water temperature directly at the taps

The author compared water temperatures at taps to a standard of $49^{\circ} \mathrm{C}$, water temperatures at hot water tanks to $60^{\circ} \mathrm{C}$, and [FAC] levels at taps to a standard of $0.2 \mathrm{mg} / \mathrm{L}$ (39).

\section{A. Descriptive Statistics}

The data recorded from temperature and [FAC] measurements at each LTCF were input into Microsoft Excel to determine measures of spread (dispersion) and measures of central tendency. The author was interested in the mean, range, minimum, maximum and standard deviation. The results from the statistical tests can be seen in Table 1 and Table 2 below:

Table 1: Tap Hot Water Temperatures $\left({ }^{\circ} \mathrm{C}\right)$

\begin{tabular}{r|l|l|l|l|l|l|}
\hline Group & $\begin{array}{l}\text { (n) } \\
\text { Samples }\end{array}$ & Mean & Range & Min & Max & $\begin{array}{l}\text { Std. } \\
\text { Deviation }\end{array}$ \\
\cline { 2 - 7 } LTCF \#I & 9 & 43.2 & 4.9 & 39.9 & 44.8 & 1.4 \\
\cline { 2 - 7 } LTCF \#2 & 16 & 38.1 & 21.4 & 22.3 & 43.7 & 6.1 \\
\cline { 2 - 7 } LTCF \#3 & 12 & 40.9 & 2.4 & 39.3 & 41.7 & 0.8 \\
\cline { 2 - 7 } ALL & 37 & 40.2 & 22.5 & 22.3 & 44.8 & 4.5 \\
\cline { 2 - 7 } & & & & &
\end{tabular}


Table 2: [FAC] Residual at Taps (mg/L)

\begin{tabular}{r|l|l|l|l|l|l|}
\hline Group & $\begin{array}{l}(\mathrm{n}) \\
\text { Samples }\end{array}$ & Mean & Range & Min & Max & $\begin{array}{l}\text { Std. } \\
\text { Deviation }\end{array}$ \\
\cline { 2 - 7 } LTCF \#1 & 6 & 0.31 & 0.11 & 0.26 & 0.37 & 0.04 \\
\cline { 2 - 7 } LTCF \#2 & 17 & 0.26 & 0.14 & 0.21 & 0.35 & 0.04 \\
LTCF \#3 & 12 & 0.27 & 0.07 & 0.22 & 0.29 & 0.02 \\
\cline { 2 - 4 } ALL & 35 & 0.27 & 0.16 & 0.21 & 0.37 & 0.04 \\
\cline { 2 - 7 } & & & & &
\end{tabular}

\section{B. Inferential Statistics}

Four inferential statistical tests were employed. A one sample t-test compared mean water temperatures at each LTCF to a standard of $49^{\circ} \mathrm{C}$. Another one sample t-test compared mean [FAC] at each LTCF to a standard of $0.20 \mathrm{mg} / \mathrm{L}$. Two ANOVA tests were employed to first, compare the difference of mean hot water temperature between all three LTCFs, and second, compare the difference of mean [FAC] between all three LTCFs.

\section{One Sample T-test Comparing Mean Hot Water Temperature}

$\mathrm{H}_{0} \quad$ There is no statistical difference between mean hot water temperature at taps and the comparison value of $49^{\circ} \mathrm{C}$

$\mathrm{H}_{\mathrm{a} 1} \quad$ Mean hot water temperature at taps will be statistically greater than the comparison value of $49^{\circ} \mathrm{C}$

$\mathrm{H}_{\mathrm{a} 2} \quad$ Mean hot water temperatures at taps will be statistically less than the comparison value of $49^{\circ} \mathrm{C}$

For all three LTCFs, the null hypothesis was rejected and it was deemed statistically significant that mean water temperatures were less than the comparison value of $49^{\circ} \mathrm{C}$ (LTCF \#1 $\mathrm{p}=0.00000, \mathrm{LTCF} \# 2 \mathrm{p}=0.00022$, LTCF \#3 $\mathrm{p}=$ $0.00110)$.

\section{One Sample T-Test Comparing Mean [FAC]}

$\mathrm{H}_{0} \quad$ There is no statistical difference between mean FAC concentration at taps and the comparison value of $0.20 \mathrm{mg} / \mathrm{L}$

$\mathrm{H}_{\mathrm{a} 1} \quad$ Mean FAC concentration at taps will be statistically greater than the comparison value of $0.20 \mathrm{mg} / \mathrm{L}$

$\mathrm{H}_{\mathrm{a} 2} \quad$ Mean FAC concentration at taps will be statistically less than the comparison value of $0.20 \mathrm{mg} / \mathrm{L}$

For all three LTCFs, the null hypothesis was rejected and it was deemed statistically significant that mean [FAC] were greater than the comparison value of $0.20 \mathrm{mg} / \mathrm{L}$ (LTCF \#1 $\mathrm{p}=$ 0.00043 , LTCF \#2 $\mathrm{p}=0.00000$, LTCF \#3 $\mathrm{p}=$ $0.00107)$.

\section{ANOVA Comparing Mean Hot Water Temperature \\ $\mathrm{H}_{0} \quad$ There is no statistical difference in mean hot water temperature at taps between the three LTCFs \\ $\mathrm{H}_{\mathrm{a} 1}$ There is a statistical difference in mean hot water temperature at taps between the three LTCFs}

The null hypothesis was rejected and it was deemed statistically significant that there was a difference in mean water temperature between the three LTCFs. The p-value was 0.00292 . Based on the post hoc Tukey-Kramer MultipleComparison Test, the mean hot water temperature of LTCF \#1 was statistically different than LTCF \#2 ( $\mathrm{p}=0.01342)$ but not statistically different than LTCF \#3 ( $p=0.43073)$. LTCF \#2 was also not statistically different than LTCF \#3 ( $p=0.17829)$.

\section{ANOVA Comparing Mean [FAC] \\ $\mathrm{H}_{0} \quad$ There is no statistical difference in mean [FAC] at taps between the three LTCFs \\ $\mathrm{H}_{\mathrm{a} 1}$ There is a statistical difference in mean [FAC] at taps between the three LTCFs}

The null hypothesis was rejected and it was deemed statistically significant that there was a difference in mean [FAC] between the three LTCFs. The p-value was 0.03481 , indicating a potential alpha error. Reducing the p-value cutoff to 0.01 would minimize this error. Power was 0.75488 , indicating some chance that the null hypothesis could be true. Based on the post hoc Tukey-Kramer Multiple Comparison Test, LTCF \#1 was statistically different than LTCF \#2 ( $p=$ $0.01562)$ and LTCF \#3 ( $p=0.02785)$, but LTCF \#2 and LTCF \#3 were not statistically different (p $=0.99238)$.

\section{DISCUSSION:}

All three LTCFs had domestic gas-fired hot water tanks installed to supply hot water. Legionella is much less likely to be detected in gas-fired hot 
water tanks as opposed to electric heaters (29). This is because gas-fired water tanks can heat the water more evenly, whereas electric tanks may experience a stratification of temperatures such that the water below the heating elements remains at a lower temperature that promotes Legionella growth (29). The hot water tanks were set at $60.6^{\circ} \mathrm{C}, 73.0^{\circ} \mathrm{C}$ and $62.0^{\circ} \mathrm{C}$ for LTCF \#1, \#2 and $\# 3$, respectively. The reason why LTCF \#2's tank was set higher than LTCF \#1 and LTCF \#2 was unknown, but is thought to be an extra precaution taken by the facility. Water that is heated to $70^{\circ} \mathrm{C}$ rapidly kills Legionella in 0 minutes, whereas water that is heated to $60^{\circ} \mathrm{C}$ kills $90 \%$ of bacteria in two minutes (40). Often times, $70^{\circ} \mathrm{C}$ is the temperature used to pasteurize and flush an already-infected system (40). However, the National Plumbing Code of Canada (NRCC) requires only that domestic hot water tanks be maintained at $60^{\circ} \mathrm{C}$ to address the growth of Legionella $(8,22)$. As such, at the times of inspection, all three LTCF's hot water tanks were meeting the requirements to prevent Legionella growth.

All three LTCFs were found to have met the typical [FAC] $(0.2 \mathrm{mg} / \mathrm{L})$ that is required in City of Vancouver distribution systems (32), with the overall LTCF average having been $0.27 \mathrm{mg} / \mathrm{L}$ ( $\mathrm{n}$ $=35$ ). According to Dalaedt et al. (2008), a concentration of $0.25 \mathrm{mg} / \mathrm{L}$ is capable of maintaining non-biofilm associated Legionella under levels capable of causing disease (31). As such, non-biofilm associated Legionella should not be a concern with the residual levels found in the LTCFs at the times of inspection. However, since Legionella pneumophila serotype 1 is often associated with a biofilm, it is more resistant to the free available chlorine concentrations typical of drinking systems and so other environmental factors must be regulated to prevent $L$. pneumophila growth (33). This is why chlorine is not the only factor to consider when it comes to the presence of Legionella in the water system.

A total of $37(n=37)$ accessible taps were measured for hot water temperature at all three LTCFs. The average hot water temperature at accessible taps was $40.2^{\circ} \mathrm{C}$, with a minimum of $22.3^{\circ} \mathrm{C}$ and a maximum of $44.8^{\circ} \mathrm{C}$. As well, the statistical results (one sample t-tests) confirmed that the hot water temperature at each tap of each LTCF was less than $49^{\circ} \mathrm{C}$. Accordingly, all three LTCFs were in compliance with the RCR Section 17 under the Community Care and Assisted Living Act which states that any water accessible to a person in care be lowered to $49^{\circ} \mathrm{C}(27)$. While temperature reduction is important to prevent scalding in LTCF residents, there is concern as to where in the system the temperature is lowered since high temperature (at least $55^{\circ} \mathrm{C}$ ) across the entire plumbing network is important to prevent Legionella growth (23). To determine where in the system the temperature was lowered to meet the RCR, maintenance personnel were asked where TMVs were installed.

As was mentioned, the average temperature at all accessible taps for all three LTCFs was $40.2^{\circ} \mathrm{C}$, which is significantly lower than the temperature requirement by the RCR. This indicated that the hot water temperature in the pipes dropped significantly after the TMV. At $40.2^{\circ} \mathrm{C}$, the hot water temperature in the plumbing systems is optimal for thriving Legionella growth (19). Since the water was previously heated to $60^{\circ} \mathrm{C}$, there should not be a problem. However, since cold water is mixed in, it has the potential to contain Legionella as the bacteria can grow in cold water that is above $20^{\circ} \mathrm{C}(20,21)$. During the winter months, this is not a concern, but during the summer months, exceptionally warm weather could increase the temperature of incoming cold water above $20^{\circ} \mathrm{C}$. If water above $20^{\circ} \mathrm{C}$ is mixed in to the heated water via the TMV and reduced to less than $49^{\circ} \mathrm{C}$ (or to the $40.2^{\circ} \mathrm{C}$ average for the three LTCFs), the temperature becomes optimal for Legionella growth if other preventative conditions are not in place. Those preventative measures include appropriate disinfection and residual, a closed loop system with no dead ends or stagnant zones and well-maintained piping. For this reason, to ensure that Legionella does not have any conditions to grow, it is best to heat incoming water at the hot water tank to $60^{\circ} \mathrm{C}$ and maintain the plumbing distribution system at $55^{\circ} \mathrm{C}$ across. To do this, it is suggested that instead of installing TMVs after the hot water tank in the boiler room, that they instead be installed directly at accessible taps before hot 
water is dispensed. That way, the hot water is maintained throughout the facility and lowered where needed.

While it was found that the three LTCFs inspected had TMVs located only within the boiler room, it is uncertain whether this is representative of all LTCFs in Vancouver. As well, it is possible for some facilities to install boosters throughout their distribution system to re-heat the water as it moves further away from the main hot water heater. There are many factors that are involved in a well-maintained plumbing distribution system to prevent Legionella proliferation, and as such, it is difficult to extrapolate results from this study to other LTCFs in Vancouver.

\section{KNOWLEDGE TRANSLATION:}

With climate change and increasing summer temperatures on the rise, it is possible that cold water in summer months may reach above $20^{\circ} \mathrm{C}$. Whether this poses a concern in terms of the location of the TMV remains to be investigated fully. This area in the plumbing system deserves more attention, especially in LTCFs where susceptible people are living. If, after more research, it is found that the location of the TMVs poses a concern for Legionella growth in some systems, it could be suggested as an extra precaution that TMVs instead be installed directly at accessible taps. As such, it may become common practice for any future renovations and LTCF developments to require that TMVs be located directly at accessible taps so that the distribution system remains heated to at least $55^{\circ} \mathrm{C}$ throughout to prevent Legionella proliferation.

\section{LIMITATIONS:}

This research project was primarily limited by time. Each LTCF was inspected and sampled within a few hours. This required the attendance of at least one maintenance personnel as well as the accompaniment of a Vancouver Costal Health Vancouver district EHO. Since the EHO had to continue their day with regular inspections, only one LTCF could be inspected each day. As well, with the researcher having only four Thursdays available to conduct her research, one of those having been used for her pilot study, this left three dates, and therefore only three LTCFs to be inspected and sampled.

To improve the study, it would be recommended that less time be spent measuring hot water temperature and chlorine residuals at taps, and instead more time be spent visiting additional LTCFs to collect information. It was found that temperature and chlorine residual did not vary drastically across the LTCFs, and so it would only be necessary to measure temperature and chlorine at even intervals throughout to represent the size and layout of the facilities. With the time saved, more LTCFs could be visited and information such as location of TMVs could be focused on. As a result, the research would have more external validity in being able to generalize what may be found at other LTCFs in Vancouver.

As well, it would have been desirable to take samples for Legionella throughout the water systems that could be analyzed by BCCDC. This would have provided solid evidence to support the temperature and chlorine measurements, and therefore improved internal validity. However, this would have added to both the time factor as well as the cost factor. As such, this research project intended to focus on the conditions for Legionella growth, rather than the presence of Legionella in the system.

\section{FUTURE RESEARCH:}

Future student projects based on Legionella and LTCFs could include:

- Conducting a survey to determine how many LTCFs in Vancouver (or another municipality) have thermostatic mixing valves installed primarily in the boiling room versus at accessible taps

- Conducting a survey to determine how many LTCFs in Vancouver (or another municipality) have water cooling towers and determining how those facilities are maintained 
It was found that all three LTCFs had set preventive measures in place to protect their residents. Water was heated to at least $60^{\circ} \mathrm{C}$ to prevent Legionella and lowered to less than $49^{\circ} \mathrm{C}$ to prevent scalding. [FAC] residual was also adequate to prevent growth of Legionella. However, the location of the TMV in the boiler room was suspected to be a possible contributing factor to Legionella growth, especially if cold water temperatures were to reach $20^{\circ} \mathrm{C}$ or above, as they could in warm summer months. It is concluded that further research is needed to determine the significance of the TMV location and the presence of Legionella. If it is confirmed to be a problem, it would be suggested that it become common practice to install TMVs directly at accessible taps instead of within the boiler room to prevent Legionella proliferation and therefore incidences of Legionnaires' disease in a vulnerable population base.

\section{ACKNOWLEDGMENTS}

The author would like to acknowledge Jessica Ip for providing helpful information at the start of the project and for putting the author in contact with Olga Bitzikos from the Communicable Disease Control department at Vancouver Coastal Health. In turn, the author would like to acknowledge the two EHOs who took her to the LTCFs to conduct her research: Tracy Au-Yeung and Virginia Jorgensen. Thank-you for your time, patience and helpful knowledge.

\section{ABBREVIATIONS:}

$\begin{array}{ll}\text { BCCDC } & \begin{array}{l}\text { British Columbia Centre for } \\ \text { Disease Control }\end{array} \\ \text { EHO } & \begin{array}{l}\text { Environmental Health Officer } \\ \text { [FAC }]\end{array} \\ & \begin{array}{l}\text { Free Available Chlorine } \\ \text { Concentration }\end{array} \\ \text { LTCF } & \text { Long Term Care Facility } \\ \text { RCR } & \text { Residential Care Regulation } \\ \text { TMV } & \text { Thermostatic Mixing Valve }\end{array}$

COMPETING INTEREST:

The author declares that there were no competing interests in the study.

\section{REFERENCES :}

1. BC Centre for Disease Control. Legionella outbreak investigation and control [Internet]. 2017 [cited 2017 Oct 5]. p. 2004. Available from: http://www.bccdc.ca/resourcegallery/Documents/Guidelines and Forms/Guidelines and Manuals/Epid/CD Manual/Chapter 1 - CDC/Legionella Guidelines.PDF

2. Fields BS, Benson RF, Besser RE. Legionella and Legionnaires' disease: 25 years of investigation. Clin Microbiol Rev [Internet]. 2002;15(3):506-26. Available from: http://cmr.asm.org/content/15/3/506.abstract?ijkey $=\mathrm{c} 4 \mathrm{f} 89 \mathrm{a} 14 \mathrm{f} 61387 \mathrm{bdacdb} 7 \mathrm{~b} 5 \mathrm{~b} 7 \mathrm{~d} 2158 \mathrm{c} 2 \mathrm{f} 99 \mathrm{~cd} 8 \mathrm{e} 4$ \&keytype2=tf_ipsecsha

3. World Health Organization. Legionellosis - Fact sheet [Internet]. 2016. Available from: http://www.who.int/mediacentre/factsheets/fs285/e $\mathrm{n} /$

4. Levesque B, Lavoie M, Joly J. Residential water heater temperature : 49 or 60 degrees Celsius? Can J Infect Dis [Internet]. 2004;15(1):2-5. Available from:

http://www.nejm.org/doi/10.1056/NEJMc1505356

5. Health Canada. Legionella. 2015.

6. Lau HY, Ashbolt NJ. The role of biofilms and protozoa in legionella pathogenesis: Implications for drinking water. J Appl Microbiol. 2009;107(2):368-78.

7. Tossa P, Deloge-Abarkan M, Zmirou-Navier D, Hartemann P, Mathieu L. Pontiac fever: An operational definition for epidemiological studies. BMC Public Health. 2006;6:1-10.

8. Health Canada. Guidance on waterborne bacterial pathogens [Internet]. 2013. Available from: https://www.canada.ca/en/healthcanada/services/publications/healthyliving/guidance-waterborne-bacterialpathogens.html

9. BCCDC. List of reportably communicable diseases in BC [Internet]. 2009. Available from: http://www.bccdc.ca/resourcegallery/Documents/Guidelines and Forms/Guidelines and Manuals/Epid/Other/Epid_Guidelines_reportable_ diseases_British_Columbia_July2009.pdf

10. World Health Organization. National passive surveillance [Internet]. Available from: http://www.who.int/immunization/monitoring_sur veillance/burden/vpd/surveillance_type/passive/en /

11. BC Centre for Disease Control. Legionellosis. In: 
BCCDC Annual Sumary 2016 [Internet]. 2016. Available from: http://www.bccdc.ca/resourcegallery/Documents/Statistics and Research/Statistics and Reports/Epid/Annual Reports/Legionellosis.pdf

12. Morshed M, Chang Y, Hoang L. Diagnostic testing for Legionnaires' disease: Trends in BC. BCMJ [Internet]. 2015;57(10):452-3. Available from: http://www.bcmj.org/bc-centre-diseasecontrol/diagnostic-testing-legionnaires'-diseasetrends-bc

13. Diederen B. Legionella spp. and Legionnaires' disease. J Infect [Internet]. 2008 Jan 1 [cited 2017 Oct 5];56(1):1-12. Available from: http://www.sciencedirect.com/science/article/pii/S 0163445307007657

14. Legionella Control. Are larger buildings a bigger Legionella risk? [Internet]. Available from: https://legionellacontrol.com/blog/230-largerbuildings-bigger-legionella-risk

15. Fitzgeorge RB, Baskerville A, Broster M, Hambleton P, Dennis PJ. Aerosol infection of animals with strains of Legionella pneumophila of different virulence: comparison with intraperitoneal and intranasal routes of infection. $\mathrm{J}$ Hyg (Lond). 1983;90:81-9.

16. Correia AM, Ferreira JS, Borges V, Nunes A, Gomes B, Capucho R, et al. Probable Person-toPerson Transmission of Legionnaires' Disease. N Engl J Med [Internet]. 2016;374(5):497-8. Available from:

http://www.nejm.org/doi/10.1056/NEJMc1505356

17. Tisinger S. Feds reimburse $\$ 4 \mathrm{M}$ for Quincy, Illinois veterans home water system [Internet]. WQAD 8. 2017. Available from: http://wqad.com/2017/02/01/feds-reimburse-4mfor-quincy-illinois-veterans-home-water-system/

18. Collier SA, Stockman LJ, Hicks LA, Garrison LE, Zhou FJ, Beach MJ. Direct healthcare costs of selected diseases primarily or partially transmitted by water. Epidemiol Infect. 2012;140:2003-13.

19. Katz SM, Hammel JM. The effect of drying, heat, and $\mathrm{pH}$ on the survival of Legionella pneumophila. Ann Clin Lab Sci. 1987;17:150-6.

20. Arvand M, Jungkind K, Hack A. Contamination of the cold water distribution system of health care facilities by Legionella pneumophila: Do we know the true dimension? Eurosurveillance.

2011;16(16).

21. Martinelli F, Caruso A, Moschini L, Turano A, Scarcella C, Speziani F. A comparison of Legionella pneumophila occurence in hot water tanks and instantaneous devices in domestic, nosocomial, and community environments. Curr Microbiol. 2000;41(5):374-6.

22. NRCC. National Plumbing Code of Canada 2015 [Internet]. 2015. Available from: https://www.nrccnrc.gc.ca/eng/publications/codes_centre/2015_nat ional plumbing code.html

23. Bédard E, Fey S, Charron D, Lalancette C, Cantin $\mathrm{P}$, Dolcé $\mathrm{P}$, et al. Temperature diagnostic to identify high risk areas and optimize Legionella pneumophila surveillance in hot water distribution systems. Water Res. 2015;71:244-56.

24. World Health Organization. WHO guidelines for drinking-water quality. [Internet]. 2011. Available from:

http://apps.who.int/iris/bitstream/10665/44584/1/9 789241548151_eng.pdf

25. Hartley D, Mccarthy A, Greenwood JE. Water Temperature From Hot Water Outlets in a Major Public Hospital : How Hot is Our Water? J Plast Surg. 2011;

26. Moritz AR, Henriques FC. Studies of thermal injury: the relative importance of time and surface temperature in the causation of cutaneous burns. Am J Pathol. 1947;23(5):695-720.

27. BC Laws. Residential Care Regulation [Internet]. 2016. Available from:

http://www.bclaws.ca/Recon/document/ID/freesid e/96_2009\#section 17

28. World Health Organization. Legionella and the prevention of Legionellosis. 2007; Available from: http://www.who.int/water_sanitation_health/emerg ing/legionella.pdf

29. Alary M, Joly JR. Risk factors for contamination of domestic hot water systems by legionellae. Appl Environ Microbiol. 1991;57(8):2360-7.

30. Health Canada. Guidelines for Canadian drinking water quality: Guidelines technical document chlorite and chlorate. 2014.

31. Delaedt Y, Daneels A, Declerck P, Behets J, Ryckeboer J, Peters E, et al. The impact of electrochemical disinfection on Escherichia coli and Legionella pneumophila in tap water. Microbiol Res. 2008;163:192-9.

32. City of Vancouver. Vancouver water utility annual report 2016 [Internet]. 2016. Available from: http://vancouver.ca/files/cov/water-quality-utilityreport-2016.PDF

33. Cervero-Aragó S, Rodríguez-Martínez S, PuertasBennasar A, Araujo RM. Effect of Common Drinking Water Disinfectants, Chlorine and Heat, on Free Legionella and Amoebae-Associated Legionella. Singer AC, editor. PLoS One [Internet]. 2015 Aug 4;10(8). Available from: http://dx.plos.org/10.1371/journal.pone.0134726

34. Storey M V., Winiecka-Krusnell J, Ashbolt NJ, Stenström TA. The efficacy of heat and chlorine treatment against thermotolerant Acanthamoebae and Legionellae. Scand J Infect Dis. 2004;36(9):656-62.

35. Armstrong TW, Haas CN. Legionnaires' disease: Evaluation of a quantitative microbial risk assessment model. J Water Health. 2008;6(2):14966.

36. Yu D, Tsang F, Eisler D, Tchao C, Man S, Yu V, et al. Development and evaluation of molecular screening assay for Legionella in water. In: Laboratory Trends, a report from the BCCDC Public Health Laboratory [Internet]. 2017. Available from: http://www.bccdc.ca/resource- 
gallery/Documents/Statistics and

Research/Statistics and Reports/Labs/Oct 2017

Laboratory Trends.pdf

37. USEPA. Technologies for Legionella Control in

Premise Plumbing Systems: Scientific Literature

Review. 2016;(September). Available from:

https://www.epa.gov/sites/production/files/2016-

09/documents/legionella_document_master_septe mber_2016_final.pdf

38. Vancouver Coastal Health. Residential facility inspection checklist [Internet]. 2013. Available from: http://www.vch.ca/Documents/Residentialcare-facility-inspection-checklist.pdf

39. Health Protection Branch M of H. British columbia guidelines (microbiological) on maintaining water quality in distribution systems. 2016;(August). Available from:

https://www2.gov.bc.ca/assets/gov/environment/ai r-land-

water/water/waterquality/monitoringwaterquality/ biomonitoring/final_distribution_systems-july-212016.pdf

40. United States Department of Labor. Legionnaire's Disease - Section II:C-1. Domestic hot-water systems. 2003; Available from:

https://www.osha.gov/dts/osta/otm/legionnaires/ho twater.html 